Article

\title{
Teleconference Use among Office Workers: An Interorganizational Comparison of an Extended Theory of Planned Behavior Model
}

\author{
Siu Hing Lo ${ }^{1}{ }^{*}$, Gerard J.P. van Breukelen ${ }^{2}$, Gjalt-Jorn Y. Peters ${ }^{3}$ and Gerjo Kok ${ }^{2}$ \\ 1 University College London, Gower Street, London WC1E 6BT, UK \\ 2 Maastricht University, P.O. Box 616, 6200 MD Maastricht, The Netherlands; \\ E-Mails: gerard.vbreukelen@ maastrichtuniversity.nl (G.J.P.V.B); \\ g.kok@maastrichtuniversity.nl (G.K.) \\ 3 Open University of the Netherlands, P.O. Box 2960, 6401 DL Heerlen, The Netherlands; \\ E-Mail: gjalt-jorn@ behaviorchange.eu (G.J.Y.P.) \\ * Author to whom correspondence should be addressed; E-Mail: s.lo@ucl.ac.uk; \\ Tel.: +44-20-3108-3099; Fax: +44-20-767-98354.
}

Received: 25 September 2013; in revised form: 3 January 2014 / Accepted: 30 January 2014 /

Published: 19 February 2014

\begin{abstract}
From a corporate social responsibility perspective, there are many reasons to promote teleconference use as an alternative to business travel. The present study examines psychosocial and organizational factors relevant to teleconference use. We tested an extended Theory of Planned Behavior model of teleconference use among office workers of four organizations. Results indicate that intention was the strongest direct predictor of teleconference use. Habit and perceived norm, in turn, were the strongest predictors of intention to use teleconference. In contrast, attitude was only weakly predictive and perceived control not predictive at all of intention to use teleconference. We also examined how this model was influenced by the organizational context by comparing organizations from two different regions, and organizations from the private $v s$. the public sector. Most teleconference-related beliefs differed between regions and organizational sectors. The relevance of specific attitudinal and normative beliefs to the overall attitude and perceived norm also differed between organizational sectors. Implications for practice and future research are discussed.
\end{abstract}


Keywords: teleconference use; organizational sector; region; office workers; theory of planned behavior; multigroup structural equation modeling

\section{Introduction}

Teleconference use has long been heralded as an alternative to physical business travel and a valuable addition to the range of tools used to communicate over distance [1-3]. Under the right conditions, teleconference meetings can be of equal quality to face-to-face meetings and substitute some business travel [3-6]. From an organizational point of view, reasons to promote teleconference use include time and money spent on traveling [1,7-9], physical and emotional toll caused by traveling [1], and greenhouse gas emissions [10]. Substituting business travel with teleconference use would therefore be an ideal corporate social responsibility goal.

However teleconference facilities remain underused, as evidenced by persistently high transportation costs [11]. Previous studies have compared user's views on specific features of computer-mediated versus face-to-face communication $[3,5,6,12,13]$. In addition to objective features of technological facilities, these studies have shown that attitudes towards and perceptions of such facilities are important influences on teleconference's success as an alternative to face-to-face meetings. Effective promotion of teleconference use thus requires a comprehensive understanding of relevant beliefs and psychosocial factors [14], as well as the organizational, cultural context in which it is used [15]. However, to our knowledge, no studies have examined teleconference use within a psychosocial framework of behavior or how the organizational context influences relevant employee perceptions and behavior. The current study addresses these research gaps by examining teleconference use within an extended Theory of Planned Behavior (TPB) framework among office workers of four organizations in the Netherlands. We tested our psychosocial model of teleconference use across a range of organizations from the private and public sector in two regions of the Netherlands. The first study aim was to test specific hypotheses (as outlined below). A secondary aim was to explore whether the TPB model applied equally to each organization, and if not, whether differences could be explained by organizational sector or region.

\subsection{Theory of Planned Behavior}

The Theory of Planned Behavior (TPB) is a generic model of social behavior that has proven useful in explaining a wide range of behaviors [16,17], including travel behaviors [18-20].

The TPB postulates that behavior is predicted by intention, which in turn is predicted by three social-cognitive factors: attitude, perceived norm and perceived behavioral control. Attitudes are an individual's overall evaluation of a behavior, which are informed by behavioral beliefs concerning a behavior's outcome (instrumental attitude) and behavioral beliefs pertaining to the experience (experiential attitude) of a behavior [17]. Perceived norms reflect the perception of other people's behavior (descriptive norms) and others' approval or disapproval (injunctive norms) of the behavior [21]. Most TPB research has employed a forced-choice format for measuring specific normative beliefs and thereby assumed familiarity with the relevant norms, but some previous research emphasized that an 
absence of relevant normative beliefs is also possible [22]. Perceived behavioral control, or self-efficacy, refers to a person's perception of the available skills and resources to perform a behavior and are reflected in an individual's control beliefs [23,24]. Relevant behavioral, normative, and control beliefs for a given behavior of interest need to be identified through pilot work [17].

However, as behaviors are performed repeatedly, they require less deliberative evaluation and eventually become habits, which are characterized by a large degree of automaticity and/or unconsciousness $[17,25]$. In this phase, contextual cues like time and place may play a more salient role in the continued performance of a behavior than social-cognitive factors [26]. For this reason, some TPB-based studies have also included habit as a predictor of behavior (e.g., [27]).

Previous TPB-based studies on travel behavior have shown that evidence generally supports the relevance of both TPB constructs and habit. A meta-analysis of psychological correlates of car use found that TPB constructs and habit were much more strongly associated with car use than pro-environmental cognitions [18]. Another study reported stronger effects of cognitive and habitual factors than socio-economic factors on travel mode choice [20].

The Technology Acceptance Model (TAM) is a simplified adaptation of the TPB aimed at explaining technology use specifically [28,29]. Unlike the TPB, which requires pilot work to identify relevant beliefs, the TAM specifies the beliefs that are relevant to technology use. It only includes perceived usefulness (PU) and perceived ease of use (PEOU) as cognitive predictors and therefore disregards the role perceived norms could potentially play. Although TAM is more parsimonious, studies comparing TAM and TPB have emphasized the ability of TPB to provide a more comprehensive understanding of technology usage in real-world, organizational settings [30,31]. Another advantage of using a generic TPB framework is that it allows for a better comparison with alternatives to teleconference use, e.g., face-to-face meetings involving travel behaviors. For these reasons, the present study will use a TPB framework. We therefore hypothesized that:

(H1) Attitude, perceived norms, perceived control and habit would together be good predictors of intention to use teleconference facilities and teleconference use (i.e., the behavior).

\subsection{Organizational Context}

Teleconference use occurs within an organizational context. There is little research on the role of organizational factors in teleconference use specifically; although the wider business travel literature suggests that organizational sector and region are particularly relevant $[7,9,32]$.

An important feature of organizations is whether they are public or private. Roughly speaking, the primary aim of public and non-profit organizations is to provide services for society or the world at large and companies aim to generate profit. Previous research provides evidence that personal values and norms differ between decision-makers of private and public sector organizations [33]. In addition, the relevance of personal values and norms to decision-making varied. In Nilsson and colleagues' study, private sector decision-makers put greater value on self-interest, although these personal values and norms were less relevant to their organizational decision-making [33]. We, thus, hypothesized that:

(H2) Beliefs related to self-interest would be better indicators of private sector than public sector employees' attitude towards teleconference use. 
Regional characteristics such as the quality of the infrastructure and travel distances can also affect business travel and teleconference use. In the Netherlands, public transport connections are often better and distances shorter in the region Zuid-Holland (the most densely-populated province and centrally-located within the Netherlands) compared with the region Limburg (one of the less populated provinces bordering Belgium and Germany; [34]). Previous TPB studies have observed regional differences in TPB and habit measures, confirming that regional characteristics influence travel-related beliefs $[19,35]$. Based on the features of the Zuid-Holland and Limburg regions outlined above and theoretical predictions derived from the TPB, we hypothesized that:

(H3a) Teleconference use would be higher among Limburg employees than Zuid-Holland employees.

(H3b) These organizational-level differences in employee teleconference use would be mediated through psychosocial factors included in the extended TPB model [17].

(H3c) Behavioral, normative and control beliefs among employees from Limburg would also be more favorable towards teleconference use compared with employees from Zuid-Holland.

\section{Methods}

\subsection{Participants and Procedure}

Employees from four organizations located in cities from the Dutch provinces Zuid-Holland (ZH) and Limburg (LB) were approached to participate in an online survey study about energy consumption among office workers. Questions about teleconference use were part of this larger survey. The sample of organizations consisted of two companies (company $\mathrm{ZH}$; company LB), a public university (university LB), and a non-governmental organization (NGO ZH), each participating with one to three office buildings located in the same city. Thus, the sample consisted of one private and one public organization in each region. The private-public divide also corresponded to the companies being more geographically dispersed within the Netherlands than the public organizations, both of which had their office building(s) in only one city. All organizations had some form of public commitment to environmental sustainability, but none had energy conservation as their primary organizational aim. However, the NGO's core task, development aid, was increasingly perceived to be related to environmental sustainability because climate change had become a pressing issue in the countries where the NGO operated [36]. Company ZH and LB were both multinational companies, which were geographically dispersed within the Netherlands. Each company participated in the study with one office building (i.e., one location) only. Company ZH employees included in this study predominantly traveled in the Netherlands and neighboring Belgium. Company LB's employee business travel patterns varied more widely between participating employees, ranging from domestic to intercontinental travel. In contrast to the companies, the vast majority of NGO ZH's participating employees were based in one office building. However, the NGO's core activity, international development aid, meant that many employees were involved in overseas activities. The university was located in one city only, but participated in the study with three office buildings.

Employees were approached by their own organization with the request to fill out the online questionnaire. It was stressed that the study was conducted by independent researchers and only the general anonymized results would be reported to the organization. Except for employees in company 
$\mathrm{LB}$, respondents were given the chance to participate in a raffle contest for $€ 20$ gift vouchers. Only respondents who traveled a minimum number of business trips per year were included in the sample to ensure that teleconference use had relevance to their business travel frequency. The inclusion criteria for domestic teleconferencing and international teleconferencing were $\geq 4$ domestic trips $(57.2 \%$ of respondents) and $\geq 1$ trip (51.1\% of respondents) per year, respectively. Although strictly speaking, the cut-off points introduced a selection bias in the sample, qualitative data from the same organizations indicated there was a broad consensus on travel frequencies around the cut-off points being unproblematic and unavoidable. Employees who traveled at frequencies below the cut-off points also perceived questions about teleconference use to be largely irrelevant to themselves. The average number of domestic trips among the total sample, 22.8 domestic trips, also suggests the domestic cut-off point was low [36].

In total, 686 respondents indicated at the beginning of the survey that they traveled at least 4 times a year within the Netherlands and 499 indicated they traveled at least 1 time a year to an international destination. Of the eligible respondents, 404 (59\%) completed the survey section on domestic teleconferencing and 321 (64\%) completed all questions on international teleconferencing. Two respondents were removed from the analysis for domestic teleconferencing because they had partially completed the relevant survey section. Of the total sample, 54\% was female, the mean age was 42 $(\mathrm{SD}=10.91)$ and $69 \%$ had received higher education. Sociodemographic descriptives of each organization's respondents are presented in Table 1.

Table 1. Sample characteristics by organization.

\begin{tabular}{lccccc}
\hline & Total & NGO ZH & Company ZH & University LB & Company LB \\
\hline Sex (\% female) & $54 \%$ & $62 \%$ & $41 \%$ & $69 \%$ & $44 \%$ \\
Education & $79 \%$ & $81 \%$ & $78 \%$ & $82 \%$ & $75 \%$ \\
(\% higher education) & & & & & 46 \\
Age (years) & 42 & 43 & 42 & 11.5 & 10.3 \\
SD & 10.9 & 9.8 & 10.9 & \\
\hline
\end{tabular}

\subsection{Measures}

Teleconference use and the measures of psychosocial factors were chosen based on findings from an earlier qualitative study conducted in the same organizations [36]. Interviews and focus groups with key informants and employees of the four organizations were conducted to identify contextual and psychosocial factors relevant to office workers' teleconference use. Based on these findings, we selected relevant adjectives for the semantic differential scales for behavioral belief measures, social referents for normative belief measures and beliefs to measure other psychosocial factors. Due to survey-length constraints, some psychosocial factors were measured with only one item. Unless stated otherwise, all measures were rated on a five-point scale ranging from 1 to 5.

\subsubsection{Teleconference Use}

We examined both domestic and international teleconference use. Behavior - the dependent variable - was measured with one item beginning with "The past year, I have used teleconference 
facilities to communicate with domestic/international contacts", rated on a scale ranging from never to very often. It should be noted that behavior, intention, and other psychosocial factors were measured concurrently. Although it is a limitation of the study design, previous research has shown that past behavior is generally a good proxy for future behavior in an unchanged environment $[27,37]$.

\subsubsection{Intention}

Behavioral intention was measured with two items stating "Next year, I expect (I1)/want (I2) to use teleconference facilities to communicate with domestic/international contacts" rated on a scale ranging from never to often.

\subsubsection{Attitude}

Attitude measures consisted of a semantic differential scale with the stem question "Using teleconference facilities to communicate with domestic/international contacts is..." and the adjective pairs "negative-positive" (IA1), "useless-useful” (IA2), "unpleasant-pleasant" (EA1), and "difficult-easy" (EA2). The adjective pairs included a mix of instrumental attitude (IA) items and experiential attitude (EA) items. Note that although "difficult-easy" is often used to measure perceived behavioural control, it often correlates more highly with experiential attitude [17]. This was also the case in this study ( $r=0.36$ vs. $r=0.69$ for domestic teleconferencing).

\subsubsection{Perceived Norms}

The injunctive norm measure consisted of two items stating "My superior(s) (ISN1)/colleagues (ISN2) think I should use teleconference facilities to communicate with domestic/international contacts" rated on a scale ranging from disagree to agree with an additional option I really do not know. The descriptive norm was measured with two items stating "My superiors (DSN1)/colleagues (DSN2) use teleconference facilities to communicate with domestic/international contacts" rated on a scale ranging from never to always and the option I really do not know. Offering the response category I really do not know allowed for a subgroup analysis of those respondents who were familiar with the relevant norm. This allowed us to examine attenuation effects due to absence of perceived norm [22]. The operational definition of this subgroup was ability to gauge the injunctive norm of superiors. We modeled injunctive and descriptive norm as first-order factors of a second-order perceived norm factor. Previous research on middle alternatives (i.e., the mid-point of a response scale) suggests that respondents often use these when they do not know the answer [38]. The answer category I really do not know was therefore recoded into the scale center (neutral for injunctive norm, and sometimes for descriptive norm) for the total sample analyses.

\subsubsection{Perceived Control}

Perceived control was measured with a single item "If I want to, I think I can manage to use teleconference facilities to communicate with domestic/international contacts" (C1) rated on a scale ranging from disagree to agree. 


\subsubsection{Habit}

For teleconferencing, habit was measured with two items adapted from Verplanken's index of habit strength: "I automatically think of the possibility to use teleconference when I need to communicate with domestic/international contacts" (H1) and "I routinely use teleconference to communicate with domestic/international contacts" (H2) rated on a scale ranging from disagree to agree [25].

\section{Results}

The overall aim was to test an extended TPB model for teleconference use and examine how this model differed between regions and organizational sectors for domestic teleconferencing. Due to the smaller number of respondents who make international business trips in all organizations and company $\mathrm{ZH}$ and university LB especially, we were unable to conduct interorganizational analyses for international teleconferencing. We also conducted various preliminary tests to test the robustness of our conclusions.

\subsection{Domestic and International Teleconference Use: Theory of Planned Behavior}

First, we tested the extended TPB model of teleconference use. We used confirmatory factor analysis (CFA) and structural equation modeling (SEM) with MPlus version 6 [39]. We verified whether the baseline model was supported by data from the total sample (H1). We also tested the baseline model on the subgroup of employees who were all familiar with the social norm to examine attenuation effects. Descriptive and basic inferential statistics of both domestic and international teleconferencing are presented by organization in Table 2 and descriptive statistics of beliefs are presented in Table 3.

Table 2. Means, SDs, and sample size of behaviors by organization.

\begin{tabular}{lcccccccc}
\hline & Total & $\begin{array}{c}\text { NGO } \\
\mathbf{Z H}\end{array}$ & $\begin{array}{c}\text { Company } \\
\mathbf{Z H}\end{array}$ & $\begin{array}{c}\text { University } \\
\text { LB }\end{array}$ & $\begin{array}{c}\text { Company } \\
\text { LB }\end{array}$ & F & $\boldsymbol{p}$-value & $\boldsymbol{\eta}^{2}$ \\
\hline $\begin{array}{l}\text { International } \\
\text { teleconferencing }\end{array}$ & 2.13 & 1.91 & 2.40 & 1.64 & 3.56 & 28.63 & $<0.001$ & 0.212 \\
$S D$ & 1.27 & 1.11 & 1.22 & 1.01 & 1.31 & 2.63 & $n s$. & - \\
$N$ & 323 & 149 & 57 & 78 & 39 & & - & - \\
\hline $\begin{array}{l}\text { Domestic } \\
\text { teleconferencing }\end{array}$ & 2.14 & 1.60 & 2.23 & 1.57 & 3.43 & 41.80 & $<0.001$ & 0.238 \\
$S D$ & 1.24 & 0.89 & 1.16 & 0.87 & 1.37 & 1.34 & $n s$. & - \\
$N$ & 404 & 95 & 184 & 69 & 58 & - & - & - \\
\hline
\end{tabular}

Italics: corrected for differences in attitude, personal norm, perceived norm, self-efficacy, habit, and intention using ANCOVA.

Both domestic and international teleconference use had some items for the latent factors violating the normality assumption (i.e., skewness and/or kurtosis values >1). Because non-normality of indicators can lead to inflated ML $\chi^{2}$ goodness-of-fit statistics and underestimated standard errors, we estimated the models with robust maximum likelihood (MLM; [40]). We followed Hu and Bentler's recommendations for evaluating goodness of fit, with around 0.95 and above for CFI (Comparative Fit 
Index) and TLI (Tucker-Lewis Index), and around 0.08 and below for RMSEA (Root Mean Square Error of Approximation) and SRMR (Standardized Root Mean Square ResidualB) as indicators of good fit [41]. Goodness-of-fit indices of the tested models are presented in Table 4. These models will be further discussed in the remainder of the results section. Correlation matrices of all latent constructs of domestic and international teleconferencing are provided in Table 5.

Table 3. Descriptive statistics beliefs.

\begin{tabular}{lcccc}
\hline & \multicolumn{2}{c}{ Domestic teleconferencing } & \multicolumn{2}{c}{ International teleconferencing } \\
& $\mathrm{M}$ & $\mathrm{SD}$ & $\mathrm{M}$ & $\mathrm{SD}$ \\
\hline$N$ & 404 & & 323 & \\
Intention (I1) & 2.62 & 1.14 & 2.60 & 1.16 \\
Intention (I2) & 2.51 & 1.15 & 2.49 & 1.14 \\
(Instrumental) attitude (IA1) & 3.93 & 1.04 & 4.07 & 1.03 \\
(Experiential) attitude (EA2) & 3.43 & 1.12 & 3.47 & 1.12 \\
(Instrumental) attitude (IA2) & 3.94 & .94 & 4.15 & .91 \\
\hline (Experiential) attitude (EA2) & 3.47 & 1.11 & 3.33 & 1.18 \\
Injunctive norm (ISN1) & 3.15 & 1.05 & 3.25 & 1.07 \\
Injunctive norm (ISN2) & 3.04 & 1.00 & 3.10 & 1.00 \\
Descriptive norm (DSN1) & 3.01 & .87 & 2.94 & .92 \\
Descriptive norm (DSN2) & 2.85 & .89 & 2.87 & .88 \\
Perceived control (C1) & 3.50 & 1.20 & 3.57 & 1.166 \\
Habit (H1) & 2.39 & 1.33 & 2.81 & 1.441 \\
Habit (H2) & 2.22 & 1.34 & 2.23 & 1.353 \\
\hline
\end{tabular}

Table 4. Teleconferencing: goodness of fit statistics.

\begin{tabular}{|c|c|c|c|c|c|c|c|c|c|c|c|}
\hline Model & $\chi^{2}$ & SB- $\chi^{2}$ & df & $\Delta \chi^{2}$ & $\Delta \mathbf{d f}$ & $\Delta \mathbf{p}$ & CFI & TLI & RMSEA & SRMR & $\begin{array}{l}\text { Scaling } \\
\text { Correct. } \\
\text { Factor }\end{array}$ \\
\hline \multicolumn{12}{|c|}{ International Teleconferencing } \\
\hline 1. CFA total sample & - & 167.130 & 54 & - & - & - & 0.959 & 0.940 & 0.081 & 0.039 & - \\
\hline 2. SEM total sample & - & 179.982 & 65 & - & - & - & 0.962 & 0.947 & 0.074 & 0.038 & - \\
\hline \multicolumn{12}{|l|}{ Domestic Teleconferencing } \\
\hline 1. CFA total sample & - & 128.558 & 54 & - & - & - & 0.978 & 0.969 & 0.058 & 0.032 & - \\
\hline 2. SEM total sample & - & 152.567 & 65 & - & - & - & 0.977 & 0.968 & 0.058 & 0.032 & - \\
\hline \multicolumn{12}{|c|}{ Domestic, Multigroup by Region } \\
\hline 3r. Region, configural & 242.994 & 219.380 & 130 & - & - & & 0.977 & 0.968 & 0.058 & 0.038 & 1.108 \\
\hline 4r. Region, equal loadings ${ }^{a}$ & 250.37 & 225.455 & 138 & 6.360 & 8 & $>0.10$ & 0.977 & 0.970 & 0.056 & 0.040 & 1.111 \\
\hline 5r. Region, equal intercepts & 335.073 & 258.632 & 143 & 90.274 & 13 & $<0.001$ & 0.970 & 0.962 & 0.063 & 0.077 & 1.100 \\
\hline \multicolumn{12}{|c|}{ Domestic, Multigroup by Sector } \\
\hline 3s. Sector, configural & 231.494 & 209.448 & 130 & - & - & & 0.978 & 0.970 & 0.055 & 0.039 & 1.105 \\
\hline 4s. Sector, equal loadings a & 255.389 & 229.38 & 138 & 19.224 & 8 & $<0.05$ & 0.975 & 0.967 & 0.057 & 0.051 & 1.113 \\
\hline 5s. Sector, equal intercepts & 335.073 & 304.883 & 143 & 99.691 & 13 & $<0.001$ & 0.956 & 0.944 & 0.075 & 0.145 & 1.099 \\
\hline
\end{tabular}

${ }^{\text {a }}$ Scaling method: loading of first indicator of each factor constrained to 1. 
Table 5. Teleconferencing: correlations between latent constructs.

\begin{tabular}{lcccccccc}
\hline & Behavior & Intention & Attitude & $\begin{array}{c}\text { Perceived } \\
\text { norm }\end{array}$ & $\begin{array}{c}\text { Injunctive } \\
\text { norm }\end{array}$ & $\begin{array}{c}\text { Descriptive } \\
\text { norm }\end{array}$ & $\begin{array}{c}\text { Perceived } \\
\text { control }\end{array}$ & Habit \\
\hline Behavior & 1.00 & 0.80 & 0.35 & 0.58 & 0.44 & 0.48 & 0.35 & 0.69 \\
Intention & 0.82 & 1.00 & 0.39 & 0.64 & 0.48 & 0.52 & 0.36 & 0.71 \\
Attitude & 0.48 & 0.52 & 1.00 & 0.37 & 0.28 & 0.31 & 0.39 & 0.43 \\
Perceived norm & 0.62 & 0.65 & 0.48 & 1.00 & 0.75 & 0.82 & 0.41 & 0.73 \\
Inj. norm & 0.43 & 0.45 & 0.34 & 0.69 & 1.00 & 0.62 & 0.31 & 0.55 \\
Descr. norm & 0.56 & 0.60 & 0.44 & 0.91 & 0.63 & 1.00 & 0.34 & 0.60 \\
Perc. control & 0.37 & 0.40 & 0.41 & 0.38 & 0.26 & 0.35 & 1.00 & 0.50 \\
Habit & 0.69 & 0.67 & 0.54 & 0.75 & 0.52 & 0.68 & 0.45 & 1.00 \\
\hline
\end{tabular}

Correlations latent constructs international teleconferencing: upper triangle above diagonal; Correlations latent constructs domestic teleconferencing: lower triangle below diagonal.

Before we addressed our primary research concerns, we first tested our measurement models on the total sample with CFA to confirm the relationship between the latent factors (i.e., psychosocial factors and intention) and their observed indicators (i.e., the measurement items). We specified indicators of psychosocial factors and intention to only load on their own factor. Measurement errors were assumed to be uncorrelated, while all factors were allowed to correlate with each other. All CFA models had an acceptable fit (see model 1 domestic and international teleconferencing in Table 4).

Subsequently, we specified a SEM model to test the hypothesized relationships between the psychosocial factors, intention and behavior. We hypothesized that (1) the latent factors attitude, social norm and perceived control all affected intention; (2) the latent factor habit affected both intention and behavior; (3) intention affected behavior. Exogenous latent factors were allowed to correlate freely because there were no hypotheses concerning the relationships between these factors. We tested the baseline model (see model 2 domestic and international teleconferencing in Table 4) on the total sample and the group of respondents familiar with social norms (H1). The explained variance of behavior was higher than that of intention for both domestic teleconferencing $\left(R_{\text {behavior }}^{2}=0.72 / R_{\text {intention }}^{2} 0.53\right)$ and international teleconferencing $\left(R_{\text {behavior }}^{2}=0.67 / R^{2}\right.$ intention $\left.=0.57\right)$. The high, explained variance in behavior can be explained by the very strong correlation between intention and behavior (Table 5). Figures 1 and 2 show the standardized factor loadings and path coefficients of the baseline models for domestic and international teleconferencing respectively. Path coefficients between parentheses indicate the estimated coefficients of psychosocial factors on intention and behavior for the subgroup familiar with the social norm.

Intention was a strong predictor of both domestic and international teleconferencing. Habit was also a significant but weaker predictor of both teleconference behaviors. For domestic teleconferencing, both perceived norm and habit had the strongest effect on intention. For international teleconferencing, habit had the strongest effect on intention, followed by perceived norm. Attitude only had a weak effect on domestic teleconferencing and no significant effect on international teleconferencing. Perceived control had no significant effect on intention for either domestic or international teleconference. Sociodemographic variables did not have any direct effects on intention or behavior. 
Figure 1. Structural equation model domestic teleconferencing (standardized loadings and path coefficients).

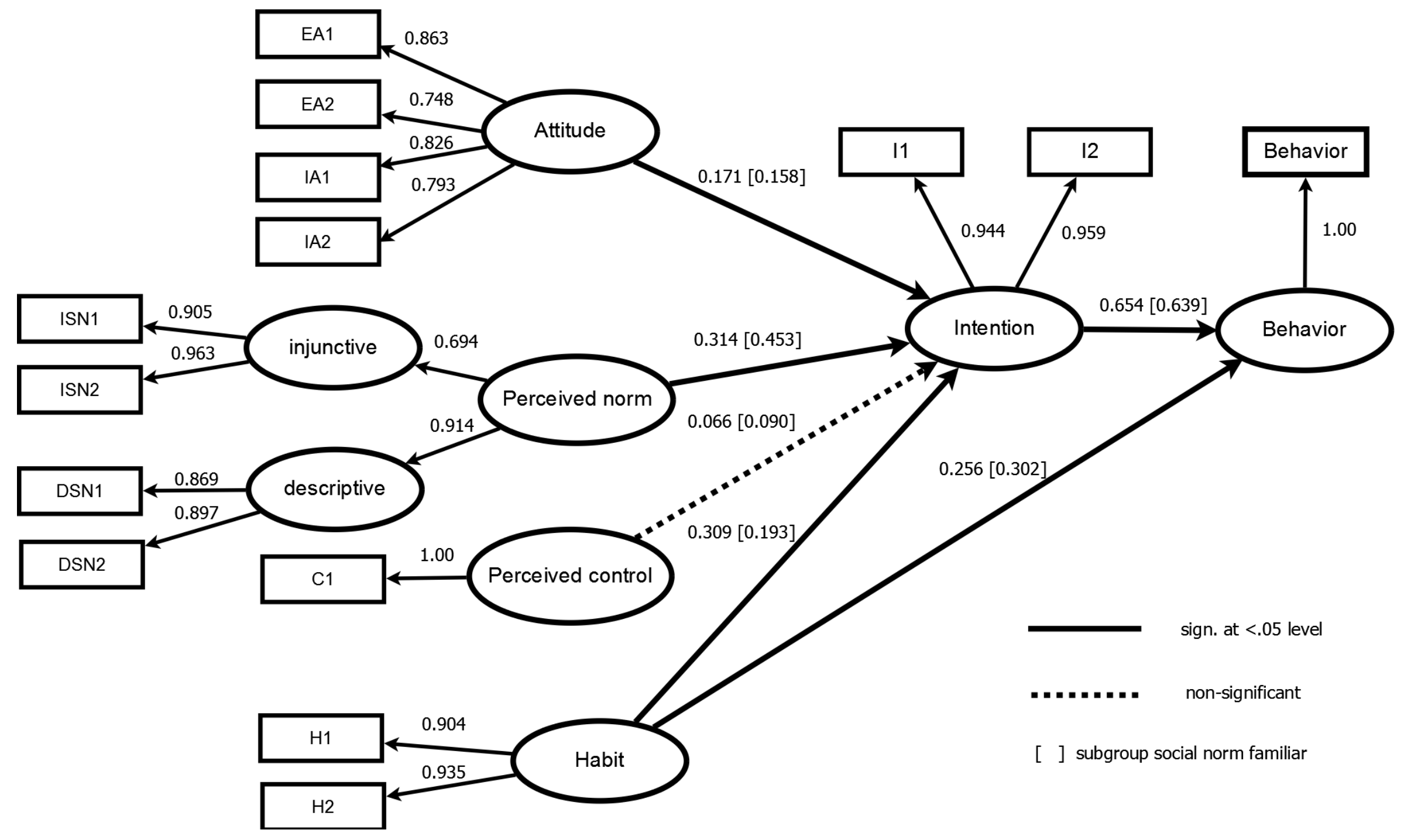


Figure 2. Structural equation model international teleconferencing (standardized loadings and path coefficients).

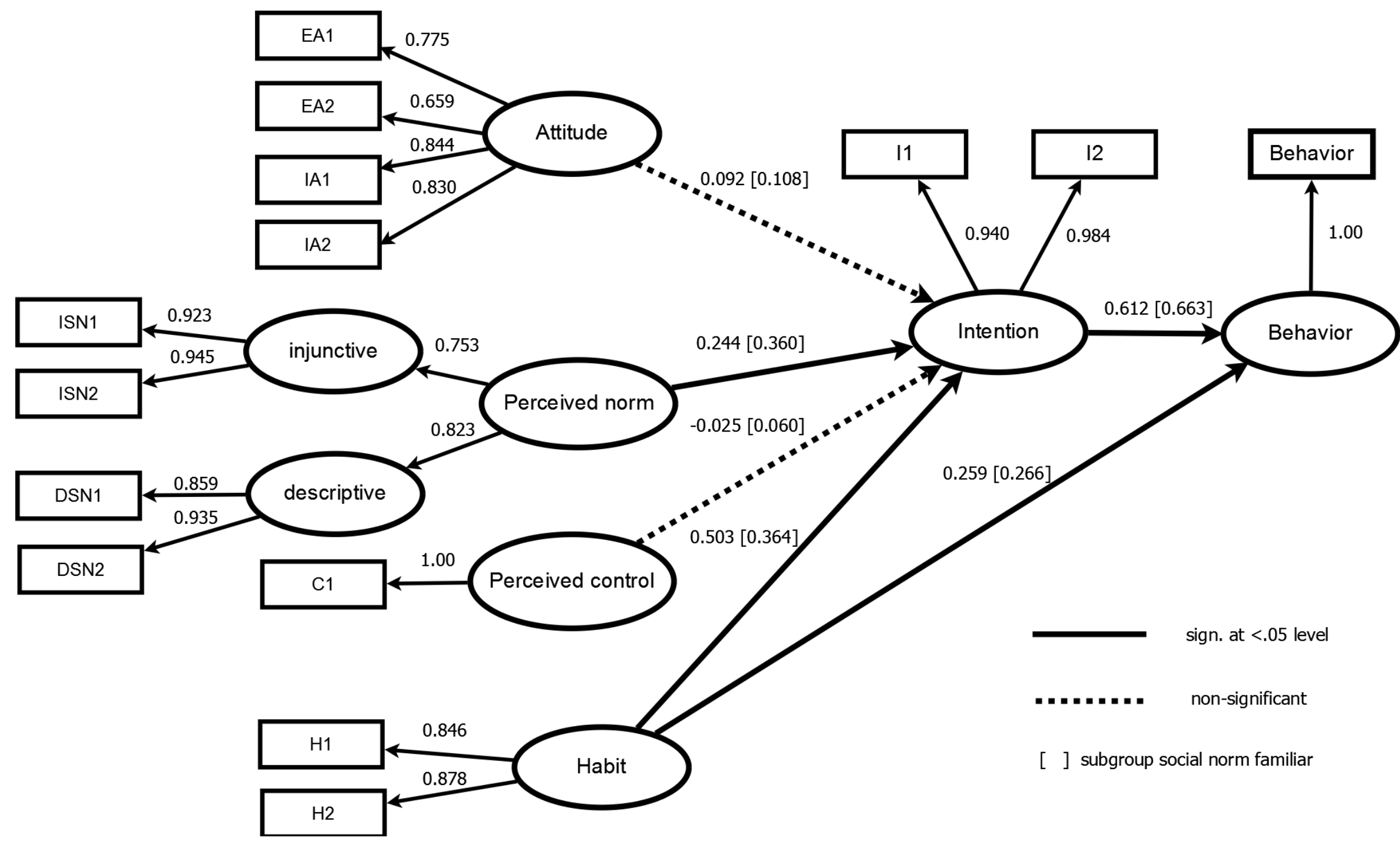


As shown in Figures 1 and 2, standardized regression coefficients for the subgroup familiar with social norms and the total sample differed considerably for the effects of perceived norms and habit on teleconference behaviors (i.e., difference > 0.10). For domestic teleconferencing, the effect of perceived norm on intention became substantially larger than that of habit, for which the effect on intention reduced. For international teleconferencing, the coefficient of perceived norm became of a magnitude comparable to that of habit. In brief, the extended TPB model was supported by the data, although not all psychosocial factors examined were significantly related to intention and behavior. The role of perceived norm and habit varied substantially between the total sample and respondents who were all familiar with the norms.

\subsection{Domestic Teleconference Use: Organizational Context}

First, we tested for organizational-level differences in teleconference use (H3a; see Table 2). We conducted one-way ANOVA (Analysis of Variance) tests and confirmed that there were significant mean differences in behaviors between the organizations. We further tested with ANCOVA whether the observed interorganizational differences in teleconference use could be explained by differences in attitude, perceived norm, perceived control, habit and intention item scores (H3b) which was confirmed for both domestic and international teleconferencing.

Following this, we conducted multigroup SEM analyses to test for sector (public vs. private) differences (H2) and regional (Zuid-Holland vs. Limburg) differences (H3c) in the extended TPB model of domestic teleconferencing.

\subsubsection{Configural Model}

For a model to be compared between groups (i.e., regions and organizational sectors), a necessary condition is configural invariance. We tested for configural invariance in a multigroup SEM, which tests an adequate fit of the baseline model for each group (see models $3 \mathrm{r}-3 \mathrm{~s}$ in Table 4). The models show acceptable goodness-of-fit indices suggesting that items are associated with the same common factors in all groups. The configural invariance model functioned as the reference model for all further multigroup analyses.

\subsubsection{Factor Loadings}

Having established acceptable configural invariance, we tested for equality of factor loadings in a multigroup SEM by constraining these loadings to be equal across groups (H2; see models 4r-4s in Table 4). A scaled $\mathrm{SB} \chi^{2}$ difference test showed that equality of factor loadings across regions held for domestic teleconferencing $\left(\Delta \mathrm{SB} \chi^{2}=6.36\right.$, $\mathrm{df}=8$, ns.; [42]). The relevance of measured beliefs to domestic teleconferencing is therefore equal across regions. Metric invariance across sectors, however, was rejected for domestic teleconferencing $\left(\Delta \mathrm{SB} \chi^{2}=19.22, \mathrm{df}=8, p<0.05\right)$.

To identify which factor loadings of domestic teleconferencing differed significantly across sectors, we conducted partial invariance tests by constraining the factor loadings of a single latent factor one at a time (see models 1si-1svi in Table 6; more details in Appendix). Equality of factor loadings was violated in the attitude and perceived norm factors, suggesting that the organizational context 
influences the extent to which specific beliefs are relevant to these psychosocial factors. In public organizations, the "easy-difficult" item had much lower loadings on the attitude factor than in the companies. This partially supports $\mathrm{H} 2$ because "easy-difficult" is more reflective of self-interest than "bad-good" and "useless-useful", although "unpleasant-pleasant"-which did not show intersector differences - is also more relevant to one's self-interest. The descriptive norm had a high loading on the second-order perceived norm factor in the companies but a low loading in public organizations; we had not predicted this sector difference.

Table 6. Domestic teleconferencing: partial measurement and structural invariance tests.

\begin{tabular}{|c|c|c|c|c|c|c|c|c|c|c|c|}
\hline Model & $\chi^{2}$ & SB- $\chi^{2}$ & $d f$ & $\Delta \chi^{2}$ & $\Delta d f$ & $\Delta p$ & CFI & TLI & RMSEA & SRMR & $\begin{array}{c}\text { Scaling } \\
\text { Correct. } \\
\text { factor }\end{array}$ \\
\hline \multicolumn{12}{|l|}{ Multigroup by Region } \\
\hline 2ri. Partial equal intercepts FA & 255.587 & 231.421 & 134 & 12.929 & 4 & $<0.05$ & 0.975 & 0.966 & 0.060 & 0.054 & 1.104 \\
\hline 2rii. Partial equal intercepts FSI & 252.482 & 228.236 & 132 & 9.721 & 2 & $<0.01$ & 0.975 & 0.966 & 0.060 & 0.044 & 1.106 \\
\hline 2riii. Partial equal intercepts FSD & 251.418 & 227.372 & 132 & 8.631 & 2 & $<0.05$ & 0.975 & 0.966 & 0.060 & 0.050 & 1.106 \\
\hline 2riv. Partial equal intercepts FSE & 256.157 & 231.307 & 131 & 13.473 & 1 & $<0.001$ & 0.974 & 0.964 & 0.062 & 0.048 & 1.107 \\
\hline 2rv. Partial equal intercepts FH & 271.568 & 245.303 & 132 & 27.422 & 2 & $<0.001$ & 0.971 & 0.960 & 0.065 & 0.084 & 1.107 \\
\hline 2rvi. Partial equal intercepts FI & 246.256 & 222.644 & 132 & 3.342 & 2 & $>0.10$ & 0.977 & 0.968 & 0.058 & 0.043 & 1.106 \\
\hline \multicolumn{12}{|l|}{ Multigroup by Sector } \\
\hline 1si. Partial equal loadings FA & 244.554 & 220.419 & 133 & 10.185 & 3 & $<0.05$ & 0.976 & 0.967 & 0.057 & 0.042 & 1.109 \\
\hline 1sii. Partial equal loadings FSI & 231.678 & 208.645 & 131 & 0.105 & 1 & $>0.10$ & 0.979 & 0.971 & 0.054 & 0.039 & 1.110 \\
\hline 1siii. Partial equal loadings FSD & 232.496 & 210.469 & 131 & 0.907 & 1 & $>0.10$ & 0.978 & 0.970 & 0.055 & 0.039 & 1.105 \\
\hline 1siv. Partial equal loadings FSN & 237.135 & 214.495 & 131 & 4.564 & 1 & $<0.05$ & 0.977 & 0.968 & 0.056 & 0.044 & 1.106 \\
\hline 1sv. Partial equal loadings FH & 234.452 & 212.078 & 131 & 2.677 & 1 & $>0.10$ & 0.978 & 0.969 & 0.055 & 0.040 & 1.105 \\
\hline 1svi. Partial equal loadings FI & 231.499 & 209.503 & 131 & 0.005 & 1 & $>0.10$ & 0.979 & 0.970 & 0.054 & 0.039 & 1.105 \\
\hline 2si. Partial equal intercepts FA & 267.153 & 242.418 & 134 & 35.499 & 4 & $<0.001$ & 0.970 & 0.960 & 0.063 & 0.067 & 1.102 \\
\hline 2sii. Partial equal intercepts FSI & 237.564 & 215.237 & 132 & 5.842 & 2 & $>0.05$ & 0.977 & 0.969 & 0.056 & 0.044 & 1.104 \\
\hline 2siii. Partial equal intercepts FSD & 267.11 & 241.916 & 132 & 34.279 & 2 & $<0.001$ & 0.970 & 0.959 & 0.064 & 0.071 & 1.104 \\
\hline 2siv. Partial equal intercepts FSE & 252.34 & 228.349 & 131 & 18.865 & 1 & $<0.001$ & 0.973 & 0.963 & 0.061 & 0.049 & 1.105 \\
\hline 2svi. Partial equal intercepts FH & 306.385 & 277.255 & 132 & 67.775 & 2 & $<0.001$ & 0.960 & 0.945 & 0.074 & 0.113 & 1.105 \\
\hline 2svii. Partial equal intercepts FI & 278.407 & 252.03 & 132 & 42.455 & 2 & $<0.001$ & 0.967 & 0.955 & 0.067 & 0.083 & 1.105 \\
\hline
\end{tabular}

FA: attitude; FSE: self-efficacy; FSN: perceived norm; FSI: injunctive norm; FSD: descriptive norm; FH: habit; FI: intention.

\subsubsection{Equality of Intercepts}

We had already established that the intercept (i.e., mean) of behavior itself differed across organizations and that psychosocial factors mediated this organizational effect (H3a-b). We would therefore also expect item intercepts for psychosocial factors to differ significantly across organizations (H3c). Equality of intercepts was tested by constraining all item intercepts except that of behavior itself to be equal across organizations in a multigroup SEM (see model $5 \mathrm{r}-5 \mathrm{~s}$ in Table 4). A scaled SB $\chi^{2}$ difference test confirmed that the equal intercepts model had a worse fit compared to the configural invariant models between regions $\left(\Delta \mathrm{SB} \chi^{2}=90.27, \mathrm{df}=13, p<0.001\right)$ and between sectors $\left(\Delta \mathrm{SB} \chi^{2}=99.69\right.$, df $\left.=13, p<0.001\right)$ for domestic teleconferencing. Thus, means of beliefs differed significantly across regions as well as sectors. 
Partial invariance tests were conducted to examine which item means differed between regions and sectors (see models 2ri-2rvii and 2si-2svii in Table 6; more details in Appendix). Item means showed that Limburg and company employees consistently had more favorable beliefs towards teleconferencing than Zuid-Holland and public sector employees, respectively, thus, supporting $\mathrm{H} 3 \mathrm{c}$ and revealing a sector difference we had not hypothesized.

\section{Discussion}

This study tested an extended Theory of Planned Behavior model for domestic and international teleconference use and analyzed how the model for domestic teleconference use differed across regions and organizational sectors.

The hypothesized extended TPB model was supported by the data, although not all psychosocial factors were significant predictors of intention and behavior. This does not contradict TPB, which states that the role each psychosocial factor plays may vary, and should be established empirically [17]. Intention was a strong, direct predictor of both domestic and international teleconference use, as postulated by the TPB. Habit was an additional significant but weaker direct predictor of domestic and international teleconference use. Habit was also the strongest overall predictor of international teleconference intentions, whereas perceived norm and habit were both strong predictors of domestic teleconference intentions. However, in the subgroup familiar with the relevant social norm, the effect of perceived norm on intentions became larger, while the effect of habit became smaller. Attitude was a significant, though weak predictor for domestic teleconference intentions but failed to predict international teleconference intentions. In brief, unlike usage of many other information technologies [29,43,44], perceived norm was a much stronger predictor of teleconference use than attitude.

Organizational-level differences in employee teleconference use were mediated through psychosocial factors incorporated in the extended TPB model. Differences in domestic teleconference use were explored in multigroup analyses by region and by organizational sector. Most regional and sector differences were found in the strength of beliefs (i.e., item intercepts) relevant to domestic teleconference use. The general pattern was that Limburg (i.e., the less densely-populated and distant region) and company employees had consistently more favorable beliefs towards teleconference use than employees from Zuid-Holland and the public sector respectively. This supports our hypothesis that a remote location and inferior transport links are associated with pro-teleconference beliefs. However, we had not hypothesized a sector difference in beliefs. One possible explanation is the geographical dispersion of the companies within the Netherlands, whereas the public sector organizations were both located in one city only. This is also in line with previous findings that organizational size (and the geographical dispersion that tends to be associated with it) is linked to higher business travel frequency, which in turn, is associated with more potential for teleconference use [5,7].

We also found sector differences in the relevance of specific beliefs (i.e., in factor loadings) to psychosocial factors in domestic teleconference use. In companies the easy-difficult item was a more important indicator of attitude than in public organizations. This is in line with the notion of self-interest being more relevant to company employees than public sector employees, a hypothesis 
supported by previous research on sector differences [33]. The relevance of injunctive versus descriptive norms to the overall perceived norm between sectors also differed, although we had not hypothesized this. However, considering the range of possible environmental, ethical, and other motivations for using teleconference facilities, there is no clear rationale why we should expect descriptive norms of teleconference use to be relevant to company employees but not public sector employees. Future research should explore possible explanations.

\subsection{Study Limitations and Future Research}

The main limitation of this study was the reliance on self-reported, cross-sectional data collected through the voluntary participation in an online survey. Having said that, the aim was not to rigorously test the validity of the theory, but to take advantage of a well-established social psychological theory to shed light on teleconference use. There is ample evidence from previous TPB studies to show that psychosocial factors are good predictors of (future) behavior, provided measurements are compatible and no relevant contextual changes occur [17]. Therefore, the current findings should be seen as a stepping-stone for future longitudinal research that can avoid potential pitfalls commonly associated with self-report and cross-sectional data. In particular, longitudinal research can address the question whether a change in relevant behavioral and normative beliefs leads to a change in subsequent teleconference use and frequency of physical travel. Similarly, we could not closely match the objective features of the teleconference facilities available to each respondent with their survey responses. Previous studies have focused on how objective features of teleconference facilities could influence its use, while this study focused on perceptions of teleconference use. Future research should examine the interaction between facility features and users' beliefs in (quasi-)experimental studies.

Another shortcoming is the measurement of perceived control with a single item. Although recent research suggests that the reliability and validity of a single-item measure can be good [45-47], conclusions drawn about perceived control are solely based on the relevance of this item rather than a comprehensive multi-item measure of the perceived behavioral control concept.

Finally, the small number of organizations in our sample prevented us from examining the role of organizational factors in more detail. Several conceptually distinguishable organizational factors could not be examined independently. For instance, the companies were more geographically dispersed than the public sector organizations in our sample. Perhaps a more fundamental issue is the lack of a conceptual understanding of organizational factors relevant to teleconference use, which also forced us to adopt a more explorative approach to examining organizational influences. Future research should examine the role of organizational policies, facilities, and culture in more depth.

\subsection{Implications for Practice}

Several conclusions for organizational practice can be drawn. Assuming a causal relationship between psychosocial factors and behavior, interventions should focus on habits and perceived norms relevant to teleconference use. Surprisingly, attitude and perceived control—often seen as the most important social-cognitive factors for technology use-seemed to play a minor or no role at all. The results also underscore the importance of identifying relevant beliefs before intervening in any organization, especially considering sector differences in the relevance of attitudinal and normative 
beliefs to employees' overall attitude and perceived norm. The results also showed substantial differences in the role of perceived norm between subgroups within organizations implying that when norms are made more salient - for instance, through a change management process - their relative influence on teleconference use could further increase. The potentially large impact of perceived norm suggests that a social marketing approach could play a valuable role in any behavior change interventions [48].

\section{Conclusions}

This study examined the psychosocial factors influencing teleconference use in various organizations. Similar to previous findings from the wider literature on organizational and travel behaviors, an extended Theory of Planned Behavior framework proved useful in explaining teleconference use. Organizational differences were mainly associated with the strength of teleconference-related beliefs. Employees in the remote region and those in companies held more favorable beliefs towards teleconference use than those in the central region and the public sector respectively. The relevance of attitudinal and normative beliefs as indicators of attitude towards and perceived norm of teleconference use also differed between public and private sector organizations.

\section{Author Contributions}

Siu Hing Lo, Gjalt-Jorn Y. Peters, Gerjo Kok conceived of and designed the study. Siu Hing Lo and Gjalt-Jorn Y. Peters collected the data. Siu Hing Lo and Gerard J.P. van Breukelen analyzed and interpreted the data. Siu Hing Lo wrote the first draft of the paper. All the authors contributed to subsequent versions of the manuscript.

\section{Conflicts of Interest}

The authors declare no conflict of interest.

\section{References}

1. Beaverstock, J.V.; Derudder, B.; Faulconbridge, J.R.; Witlox, F. International business travel: Some explorations. Geogra. Ann. Ser. B Hum. Geogr. 2009, 91B, 193-202.

2. Elliot, S. Transdisciplinary perspectives on environmental sustainability: A resource base and framework for IT-enabled business transformation. MIS Q. 2011, 35,197-236.

3. Rhoads, M. Face-to-face and computer-mediated communication: What does theory tell us and what have we learned so far? J. Plan. Lit. 2010, 25, 111-122.

4. Arnfalk, P.; Kogg, B. Service transformation-Managing a shift from business travel to virtual meetings. J. Clean. Prod. 2003, 11, 859-872.

5. Lu, J.L.; Peeta, S. Analysis of the factors that influence the relationship between business air travel and videoconferencing. Transp. Res. Part A:Policy Pract. 2009, 43, 709-721.

6. Simon, A.F. Computer-mediated communication: Task performance and satisfaction. J. Soc. Psychol. 2006, 146, 349-379. 
7. Aguilera, A. Business travel and mobile workers. Transp. Res. Part a-Policy Pract. 2008, 42, 1109-1116.

8. Davies, Z.G.; Armsworth, P.R. Making an impact: The influence of policies to reduce emissions from aviation on the business travel patterns of individual corporations. Energy Policy 2010, 38, 7634-7638.

9. Ajzen, I. The theory of planned behaviour: Reactions and reflections. Psychol. Health 2011, 26, 1113-1127.

10. Toffel, M.W.; Horvath, A. Environmental implications of wireless technologies: News delivery and business meetings. Environ. Sci. Technol. 2004, 38, 2961-2970.

11. De Groot, G.M.; Morgenstern, P.P. Energieverbruik en Besparingspotentieel Bedrijven en Instellingen (Energy Use and Saving Potential Companies and Institutions); RIVM (National Institute for Public Health and the Environment): Bilthoven, The Netherlands, 2009.

12. Anderson, J.; Ashraf, N.; Douther, C.; Jack, M.A. Presence and usability in shared space virtual conferencing: A participatory design study. Cyberpsychol. Behav. 2001, 4, 287-305.

13. Anderson, A.H.; McEwan, R.; Bal, J.; Carletta, J. Virtual team meetings: An analysis of communication and context. Comput. Hum. Behav. 2007, 23, 2558-2580.

14. Kok, G.; Lo, S.H.; Peters, G.J.Y.; Ruiter, R.A.C. Changing energy-related behavior: An Intervention Mapping approach. Energy Policy 2011, 39, 5280-5286.

15. Okereke, C.; Wittneben, B.; Bowen, F. Climate change: Challenging business, transforming politics. Bus. Soc. 2012, 51, 7-30.

16. Armitage, C.J.; Conner, M. Efficacy of the theory of planned behaviour: A meta-analytic review. Br. J. Soc. Psychol. 2001, 40, 471-499.

17. Fishbein, M.; Ajzen, I. Predicting and Changing Behavior: The Reasoned Action Approach; Taylor \& Francis Group: New York, NY, USA, 2010.

18. Gardner, B.; Abraham, C. Psychological correlates of car use: A meta-analysis. Transp. Res. Part F:Traffic Psychol. Behav. 2008, 11, 300-311.

19. Bamberg, S.; Hunecke, M.; Blobaum, A. Social context, personal norms and the use of public transportation: Two field studies. J. Environ. Psychol. 2007, 27, 190-203.

20. Chen, C.F.; Lai, W.T. The effects of rational and habitual factors on mode choice behaviors in a motorcycle-dependent region: Evidence from Taiwan. Transp. Policy 2011, 18, 711-718.

21. Schultz, P.W.; Nolan, J.M.; Cialdini, R.B.; Goldstein, N.J.; Griskevicius, V. The constructive, destructive and reconstructive power of social norms. Psychol. Sci. 2007, 18, 429-434.

22. Siero, S.; Boon, M.E.; Kok, G.J.; Siero, F.W.; Veen, P. Implementatie van energiebesparend gedrag in een grote organisatie. $M \& O$, Tijdschrift voor Organisatiekunde en Sociaal Beleid 1984, 38, 323-338.

23. Bandura, A. Self-Efficacy: The Exercise of Control; Worth Publishers: New York, NY, USA, 1997.

24. Ajzen, I. The theory of planned behavior. Organ. Behav. Hum. Decis. Processes 1991, 50, 179-211.

25. Verplanken, B.; Orbell, S. Reflections on past behavior: A self-report index of habit strength. J. Appl. Soc. Psychol. 2003, 33, 1313-1330.

26. Wood, W.; Tam, L.; Guerrero Witt, M. Changing circumstances, disrupting habits. J. Pers. Soc. Psychol. 2005, 88, 918-933. 
27. Bamberg, S.; Ajzen, I.; Schmidt, P. Choice of travel mode in the theory of planned behavior: The roles of past behavior, habit, and reasoned action. Basic Appl. Soc. Psychol. 2003, 25, 175-187.

28. Davis, F.D. Perceived usefulness, perceived ease of use, and user acceptance of information technologies. MIS Q. 1989, 13, 319-340.

29. Legris, P.; Ingham, J.; Collerette, P. Why do people use information technology? A critical review of the technology acceptance model. Inf. Manag. 2003, 40, 191-204.

30. Taylor, S.; Todd, P.A. Understanding information technology usage: A test of competing models. Inf. Syst. Res. 1995, 6, 144-176.

31. Mathieson, K. Predicting user intentions: Comparing the technology acceptance model with the theory of planned behavior. Inf. Syst. Res. 1991, 2, 173-191.

32. Gallo, P.J.; Christensen, L.J. Firm size matters: An empirical investigation of organizational size and ownership on sustainability-related behaviors. Bus. Soc. 2011, 50, 315-349.

33. Nilsson, A.; von Borgstede, C.; Biel, A. Willingness to accept climate change strategies: The effect of values and norms. J. Environ. Psychol. 2004, 24, 267-277.

34. CBS, PBL, UR W. Bevolkingsomvang en aantal huishoudens, 1980-2010. Secondary Bevolkingsomvang en aantal huishoudens, 1980-2010. Available online: http://www.compendium voordeleefomgeving.nl/indicatoren/nl0001-Bevolkingsomvang-en-huishoudens.html?i=15-12 (accessed on 3 January 2012).

35. Chen, C.F.; Chao, W.H. Habitual or reasoned? Using the theory of planned behavior, technology acceptance model, and habit to examine switching intentions toward public transit. Transp. Res. Part F: Traffic Psychol. Behav. 2011, 14, 128-137.

36. Lo, S.H.; van Breukelen, G.J.P.; Peters, G.J.Y.; Kok, G. Proenvironmental travel behaviors among office workers: A qualitative study of individual and organizational determinants. Transp. Res. Part A: Policy Pract. 2011, 56, 11-22.

37. Wright, C.; Nyberg, D.; Grant, D. "Hippies on the third floor": Climate change, narrative identity and the micro-politics of corporate environmentalism. Organ. Stud. 2012, 33, 1451-1475.

38. Sturgis, P.; Roberts, C.; Smith, P. Middle alternatives revisited: How the neither/nor response acts as a way of saying "I Don't Know”? Sociol. Methods Res. 2012, doi:10.1177/0049124112452527.

39. Muthén, L.K.; Muthén, B.O. Mplus User's Guide, 6th ed.; Muthén \& Muthén: Los Angeles, CA, USA, 1998-2010.

40. Satorra, A.; Bentler, P.M. Corrections to Test Statistics and Standard Enors in Covariance Structure Analysis. In Latent Variables Analysis: Applications for Developmental Research; von Eye, A., Clogg, C.C., Eds.; Sage: Thousand Oaks, CA, USA, 1994; pp. 399-419.

41. Hu, L.T.; Bentler, P.M. Cutoff criteria for fit indexes in covariance structure analysis: Conventional criteria versus new alternatives. Struct. Equ. Model. 1999, 6, 1-55.

42. Satorra, A.; Bentler, P.M. A scaled difference chi-square test statistic for moment structure analysis. Psychometrika 2001, 66, 507-514.

43. Venkatesh, V.; Davis, F.D. A theoretical extension of the Technology Acceptance Model: Four longitudinal field studies. Manag. Sci. 2000, 46, 186-204.

44. Yang, C.; Hsu, Y.C.; Tan, S.Y.T. Predicting the determinants of user' intentions for using YouTube to share video: Moderating gender effects. Cyberpsychol. Behav. Soc. Netw. 2010, 13, 141-152. 
45. Bergkvist, L.; Rossiter, J.R. The predictive validity of multiple-item versus single-item measures of the same constructs. J. Mark. Res. 2007, 44, 175-184.

46. Christophersen, T.; Konradt, U. Reliability, validity, and sensitivity of a single-item measure of online store usability. Int. J. Hum.-Comput. Stud. 2011, 69, 269-280.

47. Hoeppner, B.B.; Kelly, J.F.; Urbanoski, K.A.; Slaymaker, V. Comparative utility of a single-item versus multiple-item measure of self-efficacy in predicting relapse among young adults. $J$. Subst. Abuse Treat. 2011, 41, 305-312.

48. McKenzie-Mohr, D. Fostering sustainable behavior through community-based social marketing. Am. Psychol. 2000, 55, 531-537.

\section{Appendix}

\section{A1. Partial Measurement Invariance of Factor Loadings}

We hypothesized that beliefs more reflective of self-interest would be better indicators of attitude in the private sector (H3). To identify which factor loadings of domestic teleconferencing differed significantly across sectors, we conducted partial invariance tests by constraining the factor loadings of a single latent factor one at a time. For factors with significantly different factor loadings, we calculated the ratio between the lowest and the highest standardized factor loading (taken from the reference model) per indicator to gauge the magnitude of the violations. The lowest ratio of each factor and a qualitative interpretation of the sector differences are reported.

Equality of factor loadings was violated for the attitude factor $\left(\Delta \mathrm{SB} \chi^{2}=10.41\right.$, df $=3, p<0.05$, diff. ratio $=0.74)$ and the second-order perceived norm factor $\left(\Delta \mathrm{SB} \chi^{2}=4.22\right.$, $\mathrm{df}=1, p<0.05$, diff. ratio $=0.54$ ). Thus, the relative importance of attitudinal measures and the descriptive versus the injunctive norm to the respective latent factors differ across sectors. Inspection of the factor loadings in the configural invariant model revealed that, in public organizations, the "easy-difficult" item had much lower loadings on the attitude factor than in the companies. Thus, "easy-difficult" does not seem to be indicative of public employees' attitude, although it is for company employees. This partially supports H4 because "easy-difficult" is an experiential attitude item that is more exclusively relevant to self-interest than the instrumental attitude items, "bad-good" and "useless-useful", although the fourth item "unpleasant-pleasant" - that showed no sector differences - is also more relevant to self-interest. The results also show that the descriptive norm had a very high loading on the second-order perceived norm factor in the companies but a very low loading in public organizations. This suggests that what others do themselves is very indicative of the perceived norm in companies but much less so in public sector organizations. We did not predict this sector difference in perceived norm.

\section{A2. Partial Measurement Invariance of Item Intercepts}

We hypothesized that intercepts would be higher in the Limburg region (H2c). Partial invariance tests were conducted to check in which parts of the model the assumption of intercept equality was violated. Many violations were found for domestic teleconferencing. For factors with significantly different intercepts, we calculated the largest difference per factor between groups to examine the magnitude of the violations (note that the maximum mean difference is 4 for a $1-5$ scale). 
Significant regional differences were found for all individual factors of domestic teleconferencing, except for intention. The largest differences were found for habit (mean diff. $=0.80$ ) with Limburg showing higher intercepts. Although other intercepts showed regional differences of less than 0.50, there was a consistent pattern: employees from Limburg held more favorable beliefs towards teleconferencing than employees from Zuid-Holland.

Sector differences were found for all individual factors, except the injunctive norm factor. Beliefs were more pro-teleconference in companies than in public organizations, all showing mean differences approaching or exceeding 0.50. The largest differences were found for habit (mean diff. = 1.05).

(C) 2014 by the authors; licensee MDPI, Basel, Switzerland. This article is an open access article distributed under the terms and conditions of the Creative Commons Attribution license (http://creativecommons.org/licenses/by/3.0/). 